\title{
Research on Ecological Compensation in the Yellow River Basin Based on the Perspective of Game Theory
}

\author{
YongQi Zhao,", ShiHao Dong ${ }^{2}$ \\ ${ }^{1}$ Department of Management Science and Engineering, Shanxi University of Finance and Economics, Taiyuan, Shanxi,China \\ ${ }^{2}$ Department of Mechanical Engineering, Yanshan University, Qinhuangdao, Hebei, China
}

\begin{abstract}
The Yellow River Basin is an important ecological function zone in China, and it plays an important role in the national economic and social development pattern. However, the over-utilization of water resources has made the ecological and environmental problems in the river basin more and more serious. For this reason, the coordinated governance of the areas along the Yellow River basin has become very important. Based on the static game model, this paper conducts a comprehensive analysis of the coordinated governance of the Yellow River basin in the upstream and downstream areas, constructs a static game model of ecological compensation between the Shanxi and Henan governments under coordinated governance, and studies the feedback equilibrium strategies of the Shanxi and Henan governments. This article provides theoretical basis and suggestions for collaborative governance to achieve sustainable development. The game results show that: reducing the cost of protecting the ecological environment of the upstream basin, increasing the benefits of protecting the ecological environment, and increasing the amount of ecological compensation can promote the implementation of the ecological compensation policy between the upstream and downstream in the basin.
\end{abstract}

\section{Introduction}

In September 2019, the "Yellow River Basin Ecological Protection and High-quality Development Symposium" was successfully held in Zhengzhou, Henan. At the meeting, General Secretary $\mathrm{Xi}$ proposed that the ecological governance of the Yellow River Basin will be upgraded to a national strategy, which shows the coordinated governance of the Yellow River Basin Will enter a new journey. Sanmenxia City in Henan Province and Pinglu County in Shanxi Province are both located in the Yellow River Basin. Since the water of the Yellow River flows uninterruptedly, the Yellow River Basin has formed an asymmetrical distribution among the regions along the coast. This has caused the disadvantages of the mutual transfer of costs and benefits between the upper and lower reaches of the Yellow River in the areas of ecological environment management and water resources development ${ }^{[1]}$.

In this case, if the upstream Pinglu County area is active in protecting the watershed, the downstream Sanmenxia area can get positive ecological externalities from it without paying, but the upstream area cannot automatically get economic benefits and compensation from it, there will be a "free-riding" phenomenon of "upstream areas invest, and downstream areas only benefit but not invest." The upstream areas are very reluctant to invest in such "public welfare undertakings".

\footnotetext{
* Corresponding author: zyq18536353489@163.com
}

Gradually, the upstream areas' willingness to invest in ecological and environmental protection will gradually decrease and their enthusiasm will be greatly reduced. It is precisely because the upstream and downstream have different interest demands on the water resources of the river basin, the game dilemma between the upstream and the downstream on the ecological environment protection and coordinated governance of the Yellow River Basin has been generated, which has caused many problems in the governance of the Yellow River Basin and deviated from the optimal state. In the end, frequent water disputes between Shanxi and Henan provinces frequently triggered water crises. Based on the current background, it is our urgent mission to conduct in-depth research on the coordinated management of the ecological environment in the basin along the Yellow River Basin to make the Yellow River Basin high-quality and sustainable development ${ }^{[2]}$.

Many scholars have used game theory to study the ecological cooperation between upstream and downstream administrative regions. Hu Zhenhua (2016) ${ }^{[3]}$ took the Lijiang River basin as an example, based on the perspective of evolutionary game, explored the balance of interests and ecological compensation mechanisms between the upstream and downstream governments in the transboundary river basin. Xu Dawei (2012) ${ }^{[4]}$ conducted an evolutionary game analysis on the conflict of interest in ecological compensation in the river basin, and found that no matter how high or low the amount of ecological compensation negotiated by the upstream and 
downstream governments is, the optimal results cannot be achieved. Appropriate government intervention must be used to achieve the overall optimality. Gao Wenjun (2015) ${ }^{[5]}$ used evolutionary game to study the supervision and management of the upstream government for the actors in the ecological compensation of the river basin.

Through combing and reviewing the literature, it is found that in the past, scholars have used static game models to conduct relatively few studies on coordinated management of the ecological environment of the Yellow River basin. Moreover, due to the lack of a comprehensive ecological compensation mechanism, the ecological compensation responsibilities between adjacent administrative regions are often unclear, which puts the watershed environmental protection in a difficult situation. Therefore, based on the static game model with complete information, this paper attempts to systematically analyze the coordinated governance of the Yellow River Basin by the upstream and downstream governments, and uses the upstream as the main body of compensation to build a game model of ecological compensation between Shanxi and Henan governments under coordinated governance. Provide a theoretical basis for the coordinated governance of other river basins in China and the improvement of the ecological compensation mechanism.

\section{Materials and Methods}

\subsection{Basic assumptions and parameter settings}

Because of the different interest demands between the Shanxi and Henan governments, the two sides also have different combinations of strategy choices in the game process. In the upstream Pinglu County area, there are two strategies of protection and non-protection during the game, and the Sanmenxia area, which is also located in the downstream, has two strategies of compensation and non-compensation.

It is assumed that the original income obtained by the upstream Pinglu County when adopting the nonprotection strategy is $R$; $E$ is the additional net benefit obtained from the improvement of the ecological environment of the Yellow River Basin when the upstream chooses the protection strategy; $C$ is the total cost paid by the upstream when choosing a protection strategy; L is the amount of ecological compensation paid by the downstream to the upstream; $G$ is the original income of the downstream Sanmenxia area when the upstream Pinglu County chooses the non-protection strategy; $T$ is the additional benefit that the downstream obtains due to the improvement of the ecological environment of the river basin when the upstream chooses the protection strategy.

$p$ is the probability that Pinglu County in the upstream chooses a protection strategy, and $q$ is the probability that Pinglu County in the downstream chooses a compensation strategy.

\subsection{Establishment of ecological compensation game model}

Assuming that the Shanxi and Henan governments are both "rational economic people", in addition to protecting the ecological environment of the Yellow River Basin during the game, the governments of the two regions also need to maximize the interests of all parties in the game. Therefore, assuming that the Shanxi and Henan governments fully understand each other's alternative strategies and the benefit function under different strategies, the game between the two governments can be regarded as a static game with complete information. According to the determined profit function between the Shanxi and Henan governments under different strategy combinations, we can get the game matrix between the Shanxi and Henan governments, as shown in Table 1.

Table 1 Game matrix between upstream and downstream

\begin{tabular}{|c|c|c|c|}
\hline \multicolumn{2}{|c|}{} & \multicolumn{2}{|c|}{ downstream area } \\
\cline { 3 - 4 } \multicolumn{2}{|c|}{} & compensation & $\begin{array}{c}\text { non } \\
\text { compensation }\end{array}$ \\
\hline \multirow{4}{*}{$\begin{array}{c}\text { upstream } \\
\text { area }\end{array}$} & protection & $\begin{array}{c}(R+L+E-C, G+T- \\
(R+E-C, G+T)\end{array}$ & $(R)$ \\
\cline { 2 - 4 } & $\begin{array}{c}\text { non- } \\
\text { protection }\end{array}$ & $(L+R, G-L)$ & $(R, G)$ \\
\hline
\end{tabular}

\section{Results \& Discussion}

\subsection{Solving pure strategy Nash equilibrium}

First, we need to solve the pure strategy Nash equilibrium of the ecological compensation game model between upstream and downstream. According to the game matrix in Table 1, when Pinglu County adopts the protection strategy, the non-compensation strategy is the dominant strategy in the Sanmenxia area. When Pinglu County chose the non-protection strategy, the non-compensation strategy in the Sanmenxia area was also the dominant strategy. It can be concluded that no matter whether Pinglu County adopts a protection or non-protection strategy for the ecological environment of the basin, the Sanmenxia area will choose a non-compensation strategy.

However,for Pinglu County, no matter whether Sanmenxia chooses compensation strategy or noncompensation strategy, it is impossible to directly judge the pros and cons of the two strategies in Pinglu County, because the specific amount of $E-C$ is unknown.

(1)When $E-C>0$, assuming that the Sanmenxia area chooses the compensation strategy, the benefit of choosing the protection strategy in Pinglu County is greater at this time (ie $R+L+E-C>L+R$ ). When the Sanmenxia area chooses no compensation strategy, it is also $R+L+E-C>L+R$, and Pinglu County has an advantage in adopting a protection strategy. At this time, the pure strategy Nash equilibrium solution of this game is $(R+L+E-C, G+T)$, which means that the Pinglu county government chooses the protection strategy, and the Sanmenxia district government chooses the noncompensation strategy.

(2)When $E-C<0$, Sanmenxia area chooses the compensation strategy. At this time, Pinglu County 
chooses the protection strategy and the income is less than the income obtained by choosing the non-protection strategy $(R-C+L+E<L+E)$. At this time, the pure strategy Nash equilibrium solution of this game is $(L+R, G+T)$, which means that Pinglu County chooses no protection strategy, and Sanmenxia area chooses no compensation strategy. The ecological compensation game between the Shanxi and Henan governments has fallen into a "vicious circle".

Through the above analysis, we know that the pure strategy Nash equilibrium of the ecological compensation game model between Pinglu County and Sanmenxia region does not exist, and then the mixed strategy Nash equilibrium of the game model is solved.

\subsection{Mixed strategy game analysis}

The income matrices of Pinglu County in the upstream and Sanmenxia in the downstream are represented by matrices $D$ and $V$, respectively:

$$
\begin{gathered}
D=\left(\begin{array}{cc}
R+L+E-C & R+E-C \\
R+L & R
\end{array}\right) \\
V=\left(\begin{array}{cc}
G+T-L & G+T \\
G-L & G
\end{array}\right)
\end{gathered}
$$

The expected return (average return) is expressed as: $u_{D}(p, q)=p^{T} D q$

$=\left(\begin{array}{ll}p & 1-p\end{array}\right)\left(\begin{array}{cc}R+L+E-C & R+E-C \\ R+L & R\end{array}\right)\left(\begin{array}{c}q \\ 1-q\end{array}\right)$

$=p(E-C)+L q+R$

$u_{V}(p, q)=q^{T} V^{T} p$

$=\left(\begin{array}{ll}q & 1-q\end{array}\right)\left(\begin{array}{cc}G+T-L & G-L \\ G+T & G\end{array}\right)\left(\begin{array}{c}p \\ 1-p\end{array}\right)$

$=-L q+p T+G$

In order to maximize the benefits of both parties in the game, find the first derivative of $p$ and $q$ respectively, solve the mixed Nash equilibrium of the game model:

$$
\begin{aligned}
& p^{*}=E-C \\
& q^{*}=-L
\end{aligned}
$$

According to formula (4) (5), the following analysis can be obtained:

(1) When the upstream selects the protection strategy, the extra income $E$ increases, and the probability $p$ of Pinglu County to choose the protection strategy will increase at the same time. It shows that when Pinglu County protects the ecology of the watershed, the ecological environment will improve, which will bring more additional benefits to Pinglu County in terms of climate and economy, which will prompt Pinglu County to choose to protect the ecological environment of the watershed, and this protection behavior Can be maintained for a long time.

(2) When the upstream protection cost $C$ decreases and the additional net income $E$ remains unchanged, the probability $p$ of the upstream selection of a protection strategy will also increase. Therefore, one measure to make the upstream actively choose to protect the river basin environment is to reduce the cost of building largescale infrastructure as much as possible while ensuring substantial benefits.

(3) When the downstream ecological compensation amount $L$ to the upstream increases, the probability $q$ that the downstream chooses to compensate the upstream will decrease, which shows that the amount of compensation is the key factor that restricts whether the downstream will make ecological compensation to the upstream.

\section{Conclusions}

\subsection{Game analysis conclusion}

(1) As the ecological compensation in the Yellow River Basin lacks a strong long-term supervision mechanism, when the benefits of protecting the ecological environment of the upstream basin are greater than the cost paid, regardless of whether the downstream provides certain ecological compensation to the upstream, the upstream will insist on protecting the ecological environment of the basin. Then the game between the Shanxi and Henan governments will fall into a "vicious circle", and the ecological environment in the basin will be trapped in a vicious circle. Therefore, from the perspective of the long-term development of the Yellow River Basin, the lack of a long-term and powerful supervision mechanism will make ecological compensation a policy that only considers short-term benefits. Therefore, in order to ensure the existence of a long-term and powerful supervision mechanism, it is necessary to negotiate and sign a long-term effective supervision agreement between the Shanxi and Henan governments to ensure that the ecological compensation policy can be implemented effectively for a long time.

(2) The costs and benefits of environmental governance in the Yellow River Basin have become an important factor restricting the implementation of the ecological compensation policy. Whether the upstream area chooses a protection strategy, the key lies in the relative size of the ecological protection costs and the benefits obtained. However, because the economic and social benefits of river basin environmental protection are difficult to measure, the cost of protecting the ecological environment of the Yellow River Basin has become the main reason. If the direct and indirect costs of the upstream government to protect the ecological environment are relatively high, and the downstream areas cannot afford to pay more ecological compensation, The central government should increase the source of ecological compensation funds and ensure the sustainability of ecological compensation through vertical payment methods to make up the difference.

\subsection{Policy recommendations}

(1) The Shanxi and Henan governments should sign a long-term and effective ecological compensation agreement

Through game analysis, it can be seen that when the 
two regions lack a long-term and effective supervision mechanism, they will fall into the "prisoner's dilemma", Therefore, to get out of the "prisoner's dilemma" between the two regions, it is necessary to sign a long-term and effective ecological compensation agreement between the Shanxi and Henan local governments to restrict the behavior of both parties in the game.

(2) A reasonable amount of compensation should be determined between the Shanxi and Henan governments

Determining a reasonable amount of compensation can not only make up for the increased cost of ecological protection in Pinglu County, but also within the acceptable range of the Sanmenxia area, so as to ensure that the Jinyu government forms a stable (protection, compensation) strategy.

(3) Special ecological compensation laws and regulations should be established and perfected between the Shanxi and Henan governments

The state urgently needs to formulate laws and regulations applicable to ecological compensation at the national macro level to regulate the cooperation agreement between Shanxi and Henan provinces, ensure the effective implementation of the higher-level government supervision mechanism, and regulate the smooth implementation of ecological compensation.

(4) Establish an information sharing platform between Shanxi and Henan governments to improve information transparency.

The governments of Shanxi and Henan should establish an information sharing platform to avoid a "prisoner's dilemma" in the game process due to information asymmetry between upstream and downstream regions, resulting in a situation of (no protection, no compensation). For example, the upstream Pinglu County government can disclose its plan to build a large-scale chemical plant in the next few years to the downstream Sanmenxia area. As a signal, the downstream government will give priority to the compensation strategy under the pressure exerted by the upstream Pinglu County.

\section{References}

1. Cui W, Long B Q, Chen P J,Xiong W, Zhang T.Game Analysis of Main Problems in Watershed Management and Development and Utilization.J. Sichuan Environment,(2005)

2. Qu F G, Sun Y F. Research on River Basin Ecological Compensation Mechanism Based on IntergovernmentalGame.J.Population·Resources and Environment in China,24:83-88,(2014)

3. $\mathrm{Hu} \mathrm{Z} \mathrm{H}$, Liu J Y, Zhong M R, Hong K R.Benefit balance analysis of ecological compensation in transboundary watershed based on evolutionary game---Taking Lijiang River Basin as anexample.J. Economic Geography,36:42-49(2016)

4. Xu D W, Tu S Y, Chang L, Zhao Y F.Analysis of conflicts of interest in ecological compensation in river basins based on evolutionary game.J. Population-Resources and Environment in China.,22:8-14(2012)

5. GaoW J, Guo G L, Shi X S.Research on River Basin Ecological Compensation and Supervision Decisionmaking Based on Evolutionary Game.J. Environmental Science and Technology. ,38:183-187 (2015) 